\title{
Human Auditory Cortex Neurochemistry Reflects the Presence and Severity of Tinnitus
}

\author{
William Sedley, ${ }^{1 \star}$ Jehill Parikh, ${ }^{2 \star}$ Richard A.E. Edden, ${ }^{3,4}$ Valerie Tait, ${ }^{5}{ }^{\circledR}$ Andrew Blamire, ${ }^{2 \star}$ and Timothy D. Griffiths ${ }^{1 \star}$ \\ ${ }^{1}$ Institute of Neuroscience and ${ }^{2}$ Newcastle Magnetic Resonance Centre, Newcastle University, Newcastle Upon Tyne, NE1 7RU, United Kingdom, ${ }^{3}$ Russell \\ H. Morgan Department of Radiology and Radiological Science, Johns Hopkins University School of Medicine, Baltimore, Maryland 21205, ${ }^{4}$ F.M. Kirby \\ Centre for Functional MRI, Kennedy Krieger Institute, Baltimore, Maryland 21205, and 5Department of Audiology, Freeman Hospital, Newcastle Upon \\ Tyne, NE7 7DN, United Kingdom
}

It is not known why tinnitus occurs in some cases of hearing damage but not others. Abnormalities of excitation-inhibition balance could influence whether tinnitus develops and its severity if it does. Animal models of hearing damage, which also produce tinnitus based on behavioral evidence, have identified abnormalities of GABAergic inhibition, both cortically and subcortically. However, the precise relationships of GABA inhibitory changes to tinnitus itself, as opposed to other consequences of hearing damage, remain uncertain. Here, we used magnetic resonance spectroscopy to non-invasively quantify GABA in the left (LAC) and right (RAC) auditory cortices of a group of 14 patients with lateralized tinnitus (eight left ear) and 14 controls matched for age, sex, and hearing. We also explored the potential relationships with other brain metabolites (i.e., choline, $N$-acetylaspartate, and creatine). The presence of tinnitus was associated with a reduction in auditory cortex GABA concentration. Regardless of tinnitus laterality, post hoc testing indicated reductions that were significant in RAC and nonsignificant in LAC. Tinnitus severity and hearing loss were correlated positively with RAC choline but not GABA. We discuss the results in the context of current models of tinnitus and methodological constraints.

Key words: auditory cortex; choline; GABA; MR spectroscopy; tinnitus

\section{Significance Statement}

Permanently affecting one in seven adults, tinnitus lacks both widely effective treatments and adequate understanding of its brain mechanisms. Existing animal models represent tinnitus that may not be distinguishable from homeostatic responses to the auditory insults used to induce it. Human studies can be well controlled in this regard but are usually not (with few even matching control subjects for hearing loss) and are limited in scope as a result of relying solely on non-invasive recording techniques. Here, we exploit recent advances in non-invasive spectroscopic techniques to establish, in a human study tightly controlled for hearing loss and hyperacusis, that tinnitus is associated with a significant reduction in auditory cortex GABA concentration, which has implications for understanding and treatment of the condition.

\section{Introduction}

Persistent sensation of sound in one or both ears (tinnitus) commonly results from certain cases of peripheral auditory damage.

Received July 15, 2015; revised Sept. 24, 2015; accepted 0ct. 3, 2015.

Author contributions: W.S., J.P., A.B., and T.D.G. designed research; W.S., J.P., and V.T. performed research; R.A.E.E. contributed unpublished reagents/analytic tools; W.S. and J.P. analyzed data; W.S., J.P., R.A.E.E., A.B., and T.D.G. wrote the paper.

This study, along with the salary of W.S., was funded by United Kingdom Medical Research Council Grant MR/ J011207/1, and applied tools developed under Grants NIH R01 EB016089 and P41 EB015909 from the National Institutes of Health, which also provide salary support for R.A.E.E. T.D.G. is funded by Wellcome Trust Grant WT091681MA. We acknowledge and thank the following individuals and groups for their contributions to this work: Louise Ward, Tim Hodgson, and Dorothy Wallace, the radiographers at the Newcastle Magnetic Resonance Centre, for performing the MRI scans and the Audiology Department in the Newcastle Upon Tyne Hospitals NHS Foundation Trust for assistance with patient recruitment.

*W.S. and J.P. are joint lead authors, and A.B. and T.D.G. are joint senior authors.

The authors declare no competing financial interests.
Although initiated in the periphery, the importance of central mechanisms in tinnitus is highlighted by reduced spontaneous and sound-driven cochlear nerve firing, instances of exacerbation attributable to sectioning the cochlear nerve, and excessive activity in the central auditory pathway (Noreña and Farley, 2013). Although neuronal firing rates are usually elevated in noise trauma animal models, the time course and tonotopic dis-

This article is freely available online through the J Neurosci Author Open Choice option.

Correspondence should be addressed to William Sedley, Auditory Group, Institute of Neuroscience, Henry Wellcome Building, Medical School, Newcastle University, Framlington Place, Newcastle Upon Tyne, NE2 4HH, UK. E-mail:william.sedley@newcastle.ac.uk.

D0I:10.1523/JNEUROSCI.2695-15.2015

Copyright $\odot 2015$ Sedley et al.

This is an Open Access article distributed under the terms of the Creative Commons Attribution License Creative Commons Attribution 4.0 International, which permits unrestricted use, distribution and reproduction in any medium provided that the original work is properly attributed. 
tribution of these may or may not match those of the tinnitus behavior (Eggermont, 2013). However, increased synchrony between neurons has been observed, in certain studies, to begin immediately after noise trauma (thus mirroring tinnitus onset; Noreña and Eggermont, 2003) and in the tonotopic region of noise trauma (Seki and Eggermont, 2003). Human tinnitus patients exhibit excessive neural synchrony, in the form of abnormal spontaneous electromagnetic field/potential oscillations in auditory cortex (Weisz et al., 2007; Adjamian et al., 2012; Tass et al., 2012) and increased responses to sound at various levels of the central auditory pathway (Lanting et al., 2008; Melcher et al., 2009; Gu et al., 2010). Although the exact role of these different types of activity in tinnitus pathogenesis is still debated (Sedley and Cummingham, 2013; De Ridder et al., 2015), they appear important and might plausibly be produced or enhanced by deficient inhibition in the central auditory pathway. If identified, reversing such inhibitory deficiency via pharmacological or other interventions could prove effective in treating tinnitus.

\section{GABA systems in tinnitus}

The inhibitory neurotransmitter GABA is instrumental in maintaining excitation-inhibition balances. From first principles, insufficient GABAergic inhibition could underlie tinnitus, or elevated inhibition could act to compensate for it. Changes could take the form of altered gross concentration, relative distribution in the tissue, receptor affinity, or receptor density. The only relevant study measuring GABA directly compared measurements from rats with behavioral evidence of chronic tinnitus, after noise exposure, with those from unexposed controls (Brozoski et al., 2012). Significant differences were found only at the level of the auditory thalamus, contralateral to the exposed ear, with exposed rats showing lower GABA concentrations. Studies using flavoprotein autofluorescence to measure the spatial spread of neural responses have found evidence of reduced GABAergic inhibition, associated with noise trauma animal tinnitus models, in the dorsal cochlear nucleus (Middleton et al., 2011) and auditory cortex (Llano et al., 2012). Chronic salicylate exposure (which causes tinnitus) has been found to result in reduced expression of glutamic acid decarboxylase (which converts glutamate to GABA) and reduced GABA receptor affinity in the inferior colliculus of rats (Bauer et al., 2000). Although indicative of GABAergic deficiency, these studies do not uniquely attribute observed abnormalities to tinnitus specifically, as opposed to other consequences of the auditory insults applied. Indirect evidence of the importance of GABA systems in tinnitus comes from a number of human and animal studies finding improvements in tinnitus measures after administration of drugs that increase GABA concentration (Brozoski et al., 2007) or have a GABAergic action (Han et al., 2012; Zheng et al., 2012). Furthermore, withdrawal from chronic benzodiazepine use is a potent inducer of tinnitus (Busto et al., 1986, 1988), suggesting a direct relationship between GABA systems and tinnitus.

\section{Magnetic resonance spectroscopy in tinnitus patients}

Magnetic resonance spectroscopy (MRS) is a non-invasive method capable of making brain neurochemical measurements in humans and has been proposed as a potentially useful tool for studying tinnitus (Cacace and Silver, 2007). We are aware of only one published report of MRS in tinnitus (Kilicarslan et al., 2014), which measured $\mathrm{N}$-acetylaspartate (NAA) and creatine in acoustic neuroma patients but without studying other metabolites or a control group. Therefore, we applied the technique to the bilateral auditory cortices of a group of chronic tinnitus patients and age/hearing-matched controls to highlight abnormalities specifically linked to tinnitus. Given the pre hoc focus on GABA, we used methods optimized for GABA estimation.

\section{Materials and Methods}

Subjects. We studied a group of 14 patients (six females) with predominantly or entirely unilateral tinnitus (eight left, six right) and 14 controls (seven females) matched for age and hearing loss. Lateralized tinnitus was studied to assess hemispheric bias of any neurochemical changes in terms of left versus right and ipsilateral versus contralateral. Exactly half of each group had normal ( $<20 \mathrm{~dB}$ hearing loss) mean hearing thresholds in frequencies between 0.25 and $8 \mathrm{kHz}$ so that the effects of hearing loss on cortical neurochemistry could be studied. Exclusion criteria included any neurological disorder other than tinnitus, the use of sedating or GABA acting medications, and contraindications to MRI.

Assessment of tinnitus phenomenology. The diagnosis of tinnitus was made based on a clinical history of persistent simple auditory percepts heard all or most of the time, when not being masked by environmental sounds, for a duration of $>6$ months. Controls were screened for the presence of tinnitus and excluded if they experienced any persistent sounds in either ear on a regular or permanent basis. Quantification of tinnitus severity was performed in three ways: (1) completion of the tinnitus handicap inventory (THI; Newman et al., 1996), which measures the effect of tinnitus rather than its loudness; (2) visual analog scoring (VAS) of subjective tinnitus loudness; and (3) VAS assessment of the distress caused by tinnitus. VAS measures were indicated on a continuous scale from 0 to 10 , with 0 being no sound at all or no distress, and 10 being the loudest sound in existence or the most distress it is possible to experience. In a novel approach to disentangling chronic from acute influences on tinnitus (which might have different correlates), for each VAS, subjects provided four responses: (1) an "average" measure, indicating their response with respect to a typical or average day; (2) a "minimum" response, indicating their lowest score applicable over the past 3 months; (3) a "maximum" response, indicating their highest score applicable over the past 3 months; and (4) a "now" measure, indicating their response applicable at the time of the experiment. These measures were converted to two values to be used for the analysis of MRS data: (1) an "overall" score, which was simply the average response; and (2) a "current" score, derived from interpolation, onto a scale of $0-10$, of the now score between the minimum and maximum responses, such that the minimum response was 0 , the average response was 5 , and the maximum response was 10. Hyperacusis was quantified in all subjects using the hyperacusis questionnaire (HQ; Khalfa et al., 2002). Audiological assessment for all subjects included pure tone audiometry (PTA) in $1 \mathrm{~dB}$ steps at frequencies of $0.25,0.5,1,2,4,6$, and $8 \mathrm{kHz}$. PTA was performed in ascending frequencies in the left and then the right ear, with three repetitions of each frequency in immediate succession, and the median value across the three repetitions was taken.

MRS acquisition. GABA has three distinct peaks in its magnetic resonance spectrum, but each of these coincides in frequency with the peak of a more abundant metabolite, necessitating the use of a specific GABA measurement technique to quantify its concentration (Puts and Edden, 2012; Mullins et al., 2014). We used the Mescher-Garwood proton resolved spectroscopy (MEGA-PRESS) technique (Mescher et al., 1998), in which alternate acquisitions are applied an editing pulse at $1.9 \mathrm{ppm}$, which modulates all three of the GABA peaks attributable to J coupling. Subtraction of the EDIT-OFF from EDIT-ON spectra thus allows separation of the GABA signal at $3 \mathrm{ppm}$ from the overlying creatine signal. MEGA-PRESS spectra were acquired from each of the left (LAC) and right (RAC) auditory cortex of each subject on a Phillips Achieva 3 Tesla MRI scanner using an eight-channel head coil. Specific sequence parameters included the following: TR, $2000 \mathrm{~ms}$; TE, $68 \mathrm{~ms}$; 320 averages; acquisition bandwidth, $1000 \mathrm{~Hz}$; scan duration, $11 \mathrm{~min}$; sinc Gaussian editing pulse applied at $1.9 \mathrm{ppm}$ (during EDIT-ON scans) and $7.5 \mathrm{ppm}$ (during EDIT-OFF scans); voxel size, 45 (anteroposterior) $\times 32$ (right to left) $\times 20$ (foot to head) $\mathrm{mm}$ for both LAC and RAC; variable power radiofrequency pulses with optimized relaxation delays (VAPOR) water suppression (Tkác et al., 1999). Non-water-suppressed spectra were also 


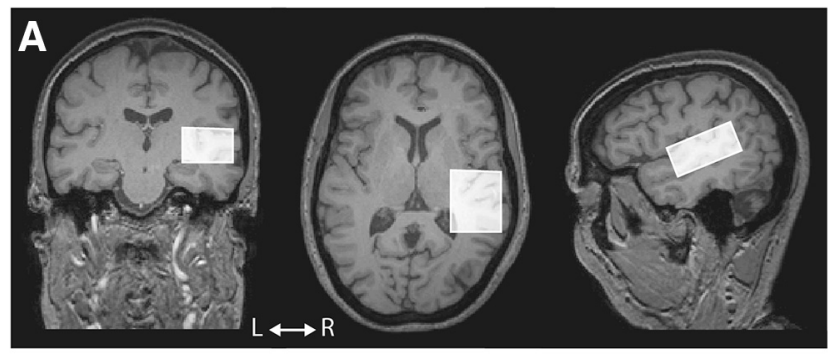

B

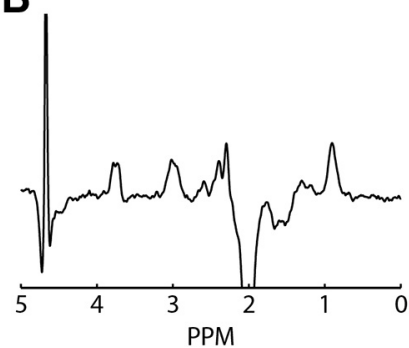

C

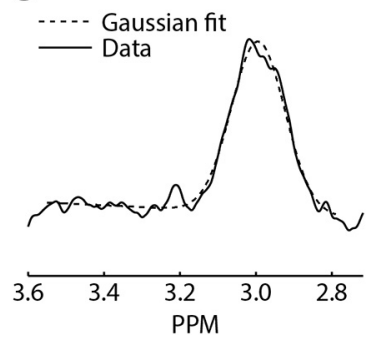

Figure 1. Example GABA spectrum acquisition from the RAC in one typical subject. $\boldsymbol{A}, 0$ rthogonal section view (neurological convention; L, left; $R$, right) of voxel placement. Voxels were placed parallel with and superiorly abutting the Sylvian fissure and were otherwise centered on Heschl's sulcus. This volume encompassed nearly all of Heschl's gyrus, including the primary auditory cortex, the planum temporale, the superior temporal sulcus, planum polare, and also small parts of the insula and middle temporal gyrus adjacent to these auditory regions. $\boldsymbol{B}$, Edited spectrum, including the GABA peak for quantification at $3 \mathrm{ppm}$. $\boldsymbol{C}$, Expanded view of $\boldsymbol{B}$, showing 3 ppm GABA peak and fitted Gaussian function used for quantification.

obtained from each auditory cortex (PRESS: TE, $68 \mathrm{~ms}$; TR, $2000 \mathrm{~ms} ; 10$ averages). Previous T1w structural scans (3D MPRAGE; sagittal acquisition aligned with the anterior commissure-posterior commissure line; 1 $\mathrm{mm}$ isotropic resolution; matrix, $240 \times 240 \times 180$; TR, $9.6 \mathrm{~ms}$; TE, 4.6 $\mathrm{ms}$; flip angle, $8^{\circ}$; sensitivity-encoded factor 2 ) were acquired to aid positioning of the MRS voxels in the LAC and RAC (for details, see Fig. 1). Macromolecular suppression editing was not performed to maximize the signal-to-noise ratio for GABA+ (i.e., GABA plus macromolecules) quantification using the MEGA-PRESS acquisition (Edden et al., 2012). To reduce sources of noise or bias, all subjects were requested to refrain from alcohol for $24 \mathrm{~h}$ before the study and caffeine on the day of the study, scans were performed at approximately the same time each morning, the scanner was not used after any high-demand sequences to prevent scanner frequency drifts that might have influenced the MEGAPRESS acquisition (Harris et al., 2014), and LAC and RAC were scanned in random order. Subjects all listened to music or radio during the acquisition of the structural T1 image and voxel placement and had no acoustic input besides scanner noise during MRS acquisition.

Spectroscopy data analysis. GABA quantification was performed using the Gannet toolbox for MATLAB (Edden et al., 2014) and comprised the following steps: (1) alignment of each pair (EDIT-ON and EDIT-OFF) of spectra (Near et al., 2014); (2) subtraction of edited spectra, to yield GABA spectra, and averaging across acquisitions; and (3) fitting a Gaussian function to the GABA peak at 3 ppm and quantifying GABA based on the area under the curve. For one typical edited spectrum and Gaussian fit, see Figure 1, $B$ and $C$, respectively. Water level was obtained from a Gaussian-Lorentzian fit to the non-water-suppressed data. Tissue fractions of gray matter (GM), white matter (WM), and CSF within the MRS voxels were calculated based on automated segmentation in SPM12 (http://www.fil.ion.ucl.ac.uk/spm/software/spm12/), using a volume mask generated from the voxel position in Gannet (Harris et al., 2015). The final measurement of interest, GABA concentration, was estimated relative to water amplitude, accounting for metabolite relaxation times and tissue fractions, as discussed by Gao et al. (2015). Choline, creatine, and NAA amplitudes were quantified from non-edited spectra only using the AMARES (Advanced Method for Accurate, Robust, and Efficient Spectral fitting of MRS data with use of prior knowledge) algorithm from
Table 1. Metabolite concentrations for tinnitus and control groups

\begin{tabular}{|c|c|c|c|c|c|c|c|}
\hline & \multicolumn{3}{|l|}{ LAC } & \multicolumn{3}{|l|}{ RAC } & \multirow[b]{2}{*}{$\begin{array}{l}\text { Combined } \\
p\end{array}$} \\
\hline & $\begin{array}{l}\text { Control }(\mathrm{mm} / \mathrm{L}), \\
n=14\end{array}$ & $\begin{array}{l}\text { Tinnitus (mM/L), } \\
n=14\end{array}$ & $p$ & $\begin{array}{l}\text { Control } \\
(\mathrm{mm} / \mathrm{L})\end{array}$ & $\begin{array}{l}\text { Tinnitus } \\
(\mathrm{mm} / \mathrm{L})\end{array}$ & $p$ & \\
\hline GABA & $1.08(0.24)$ & $0.99(0.13)$ & 0.30 & $1.28(0.12)$ & $1.12(0.10)$ & 0.018 & 0.015 \\
\hline Choline & $2.72(0.60)$ & $2.60(0.38)$ & & $3.43(0.82)$ & $3.23(0.71)$ & & 0.15 \\
\hline NAA & $13.5(2.17)$ & $13.7(1.64)$ & & $15.2(2.22)$ & $15.3(1.47)$ & & 0.67 \\
\hline Creatine & $8.03(2.36)$ & 7.76 (1.48) & & $9.75(2.13)$ & $9.61(4.22)$ & & 0.21 \\
\hline
\end{tabular}

When applicable, values are median (interquartile range). Combined $p$ values are uncorrected (although GABA represents a primary hypothesis) and are based on Friedman's test, treating hemisphere as a blocking variable. Where these are significant, $p$ values are shown for the LAC and RAC, which are based on Wilcoxon's rank-sum tests. Significant group differences are shown in bold.

jMRUI (Naressi et al., 2001), and similarly to GABA were converted to tissue concentrations by taking account of water level, tissue fractions, and known tissue metabolite relaxation times from the literature (Mlynárik et al., 2001; Ethofer et al., 2003). As part of the quality assurance routine, MRS fit quality was assessed by an experienced physicist; the spectra were rejected if the Gannet fit error was $>10 \%$ (GABA measurements) or metabolite line width was $>12 \mathrm{~Hz}$ (NAA, creatine, and choline).

Statistical analysis. Nonparametric statistics were used, namely the Friedman's test for main effects of group, with Wilcoxon's rank-sum test for post hoc group differences in individual hemispheres, and Spearman's rank correlation coefficients for correlations with tinnitus-related or other continuous variables. GABA was treated as the primary outcome measure and therefore was not subject to multiple comparison correction. Choline, creatine, and NAA were treated as exploratory and therefore subject to Bonferroni's correction. All statistical tests were two tailed.

\section{Results}

\section{Spectroscopy results overview}

Gaussian fit errors of the GABA spectra were all $<10 \%$, except for one subject in whom the LAC fit error was $15 \%$. This spectrum was reacquired, with an equal fit error in the second acquisition, and the GABA values obtained from the two spectra were averaged. All line widths for non-GABA metabolites were $<12 \mathrm{~Hz}$. Table 1 shows all metabolite concentrations for tinnitus and control groups. It can be seen from this that all metabolites were less abundant in LAC than RAC by $\sim 20 \%$. The absence of any relative differences between metabolites suggests that this was an issue of decreased signal from a particular voxel location, as has been reported in phantom studies (Edden and Barker, 2007), as opposed to chemical shift misregistration; in this phenomenon, the spatial distance between the intended and sampled voxel locations varies for the different metabolites, thus producing varying degrees of signal loss (as opposed to the consistent 20\% reduction we observed).

\section{GABA spectroscopy results}

Compared with controls, the tinnitus group showed GABA decreases in the LAC (median, 0.99 vs $1.08 \mathrm{~mm} / \mathrm{L}$ ) and RAC (median 1.12 vs $1.28 \mathrm{~mm} / \mathrm{L})$. Friedman's test showed a significant main effect of subject group ( $p=0.015)$, and Wilcoxon's ranksum tests found the difference to be significant in the RAC ( $p=$ $0.018)$ but not LAC ( $p=0.30)$. The reduction in RAC GABA concentration in the tinnitus group remained significant $(p=$ 0.0308 ) after excluding a control outlier from the analysis. These results are shown in Table 1 and Figure 2. There was no significant difference in RAC GABA concentration between the left and right ear tinnitus patients $(p=0.85)$. GABA concentrations showed no significant correlation with age, sex, hearing loss, hyperacusis, or any of the tinnitus severity measures. 


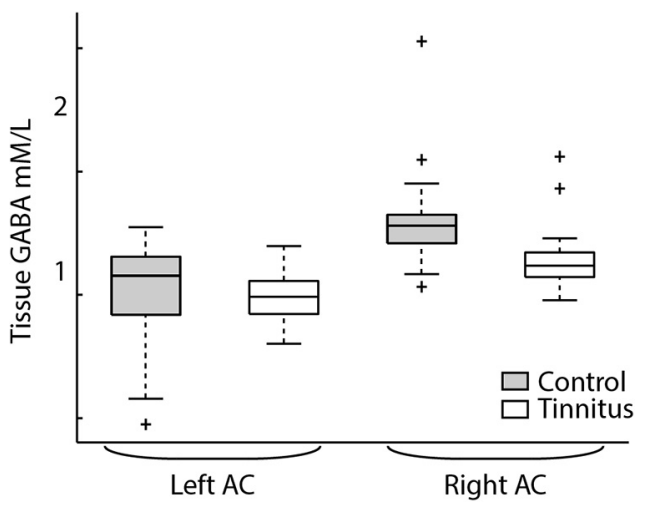

Figure 2. Auditory cortex GABA concentrations in the tinnitus and control groups. AC, Auditory cortex. Boxes indicate interquartile range, with horizontal line at the median, and whiskers indicate full range, barring outliers that are indicated with + signs. GABA was significantly reduced ( $p<0.05$ ) as a main effect of subject group (tinnitus vs control) and in the RAC. Results displayed here are also tabulated in Table 1.

Table 2. Subject characteristics of tinnitus and control groups

\begin{tabular}{llll}
\hline & Control & Tinnitus & Difference $(p)$ \\
\hline Group size $(n)$ & 14 & 14 & \\
Age (years) & $55.7 \pm 10.6$ & $53.7 \pm 15.1$ & 0.87 \\
Sex ( $n$ females) & 7 of 14 & 6 of 14 & \\
Mean left-ear hearing loss (dB) & $19.4 \pm 14.4$ & $18.8 \pm 15.3$ & 0.91 \\
Mean right-ear hearing loss (dB) & $17.4 \pm 11.5$ & $18.0 \pm 20.2$ & 0.58 \\
Hyperacusis (HQ) & $11.6 \pm 5.7$ & $13.6 \pm 6.4$ & 0.30 \\
$t$ duration (years) & & $9.4 \pm 7.6$ & \\
Laterality ( $n$ left) & & 8 of 14 & \\
THI & & $26.7 \pm 13.2$ & \\
Overall loudness & & $3.9 \pm 1.8$ & \\
Current loudness & & $4.3 \pm 2.3$ & \\
Overall distress & & $3.1 \pm 1.6$ & \\
Current distress & & $3.9 \pm(2.2$ &
\end{tabular}

When applicable, values are indicate mean $\pm S D$. $p$ value is between the tinnitus and control groups based on Wilcoxon's rank-sum statistic.

\section{Subject characteristics}

Fourteen tinnitus patients and an equal number of matched controls were studied. No significant differences were present between groups in terms of age, hearing loss in either ear, or hyperacusis. There was one extra female subject in the control group compared with the tinnitus group. Mean tinnitus duration was 9.4 years (range, 2-29 years). Eight of the tinnitus patients had left-ear-predominant tinnitus compared with 6 right ear. Table 2 summarizes the group characteristics and Figure $3 A$ the group hearing thresholds.

There were significant positive correlations between certain tinnitus measures, as illustrated in Figure 3B. Most notably, THI score correlated with hearing loss and hyperacusis, and VAS overall tinnitus distress score correlated positively with HQ, THI, and VAS overall tinnitus loudness scores. Based on these correlations and our relative interest in certain measures above others, we eliminated hyperacusis and overall VAS distress from additional analysis.

\section{Structural brain changes}

There were no (uncorrected) significant differences in GM, WM, or CSF concentrations in the LAC or RAC between the tinnitus and control groups. However, in the subject group as a whole, GM fraction correlated negatively with both age (LAC, $\rho=$ $-0.57, p=0.0016$; RAC, $\rho=-0.48, p=0.009$ ) and hearing loss (LAC, $\rho=-0.59, p=0.001$; RAC, $\rho=-0.49, p=0.0078$ ), and
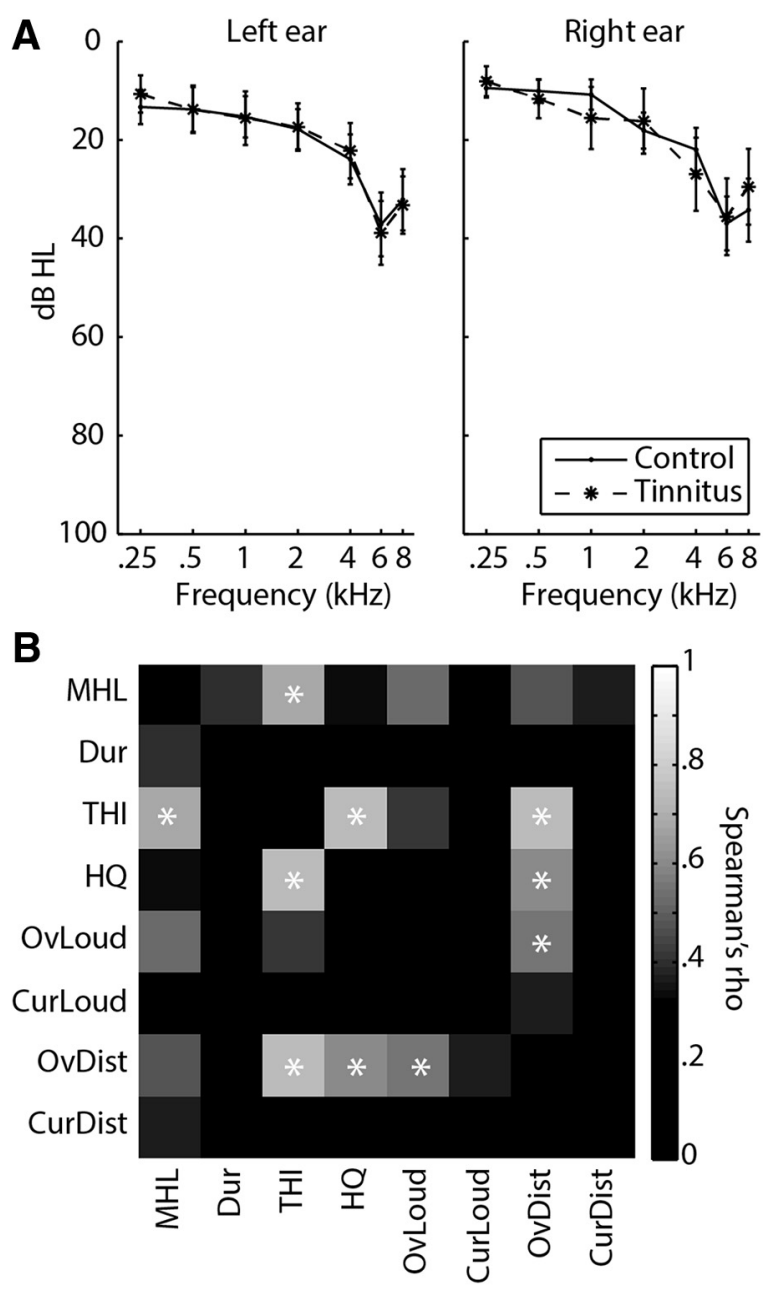

Figure 3. Hearing and tinnitus-related subject characteristics. $\boldsymbol{A}$, Mean pure tone hearing thresholds of the tinnitus and control groups. Error bars represent SEM. B, Positive nonparametric correlations between hearing and tinnitus measures within the tinnitus group. Significant ( $p<0.05$ uncorrected) correlations are denoted by asterisks. No negative correlations close to significance were observed, hence only positive correlations are shown. MHL, Mean hearing loss (in decibels; across all frequencies shown in $\boldsymbol{A}$ ). Dur, Tinnitus duration (years); OvLoud, overall VAS loudness; CurLoud, current VAS loudness; OvDist, overall VAS tinnitus distress; CurDist, current VAS tinnitus distress.

CSF fraction correlated positively with age (LAC, $\rho=0.52, p=$ 0.0047; RAC, $\rho=0.56, p=0.0019$ ) and hearing loss (LAC, $\rho=$ $0.25, p=0.20$; RAC, $\rho=0.40, p=0.033$ ).

\section{Choline spectroscopy}

Choline concentration was not significantly different between the tinnitus and control groups (see Table 1). RAC choline correlated with overall VAS tinnitus loudness $(\rho=0.050, p=0.069$ uncorrected $)$, THI score $(\rho=0.73, p=0.034$ corrected $)$, hearing loss in the subject group as a whole $(\rho=0.62, p=0.0055$ corrected $)$, hearing loss in the tinnitus group $(\rho=0.81, p=0.0078$ corrected), and hearing loss in the control group $(\rho=0.41, p=0.14$ uncorrected). These correlations are illustrated in Figure 4. Because choline is present in higher concentrations in WM than GM (Rae, 2014) and tissue composition correlated with age and hearing loss, we repeated significant correlation analyses after partialing out age, hearing loss, and all tissue fractions from both RAC choline concentration and the subject variable of interest. It should be kept in mind that such extensive partialization removes a lot of variance from the data, so the same strength of correlation 
A

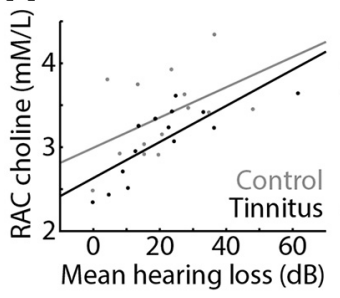

B

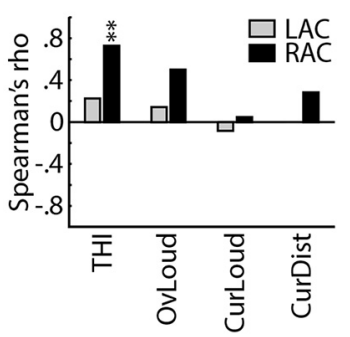

Figure 4. Correlations between choline concentration and subject variables. $A$, Relationship between mean hearing loss and RAC choline concentration in control (gray) and tinnitus (black) groups. Individual dots denote individual subjects, and lines represent least squares best linear fits. $\boldsymbol{B}$, Spearman's rank correlation coefficients $(\rho)$ between choline and subjective tinnitus variables in bilateral auditory cortices. OvLoud, VAS overall tinnitus loudness; CurLoud, VAS current tinnitus loudness; CurDist, VAS current tinnitus distress. ${ }^{* *} p<0.01$ uncorrected.

cannot be expected. Nonetheless, these partial analyses showed that the correlation between hearing loss and choline in the whole subject group remained significant $(\rho=0.39, p=0.040$ uncorrected), and the majority of the correlation between choline and THI score remained ( $\rho=0.41, p=0.15$ uncorrected).

\section{NAA and creatine spectroscopy}

There were no group-level differences between tinnitus and control groups for NAA or creatine, in either auditory cortex, even before Bonferroni's correction. Choline and NAA both reflect neuronal density (Miller et al., 1996); therefore, we tested whether there were similar correlations with hearing loss and THI scores with NAA, as there were for choline, which might indicate a structural basis to observed changes. NAA did not correlate significantly with either mean hearing loss $(p=0.95$ uncorrected) or THI score ( $p=0.76$ uncorrected).

\section{Discussion}

We studied a group of tinnitus patients and controls matched for age, sex, hearing loss, and hyperacusis; thus, observed differences can reasonably be inferred to relate to tinnitus as opposed to any of these confounding factors. Because we did not perform macromolecule suppression, for reasons of preserving the signal-tonoise ratio and allowing greater robustness to subject motion, all GABA results should be considered as indicating GABA+ (i.e., GABA plus macromolecules). This means that, as with a large proportion of human MRS studies of GABA, there is a theoretical possibility that a proportion of the findings might relate to molecules other than GABA. MRS measurements were made from a large voxel spanning almost all of auditory cortex, encompassing primary and association areas, and including some areas of surrounding non-auditory cortex. Although the primary reason for using such a large sampling area was to provide a robust GABA measurement, it is likely to have been appropriate in tinnitus, in which ongoing abnormal neurophysiological signals have been found to occur across a correspondingly large anatomical area as opposed to just circumscribed parts of the auditory cortex (Sedley et al., 2015). However, the exact size and position of the voxel used could influence the sensitivity of our measurements to detecting changes in other factors that might correlate with neurotransmitter concentrations in more localized parts of the auditory cortex. Such a voxel size and placement issue might explain why we did not observe a relationship between GABA concentration and hearing loss, as was reported recently in association with age-related hearing loss (Gao et al., 2015). Spe- cifically, voxels in the present study were placed to capture as much of auditory cortex as possible and as little of non-auditory areas, which meant that the primary auditory cortex was at the superior edge of the voxel and slightly anterior of center. Conversely, Gao et al. centered voxels on Heschl's gyrus and therefore on or near the primary auditory cortex. Thus, it is possible that their results were relatively more strongly influenced by the primary auditory cortex than those in the present study. However, our study had other methodological differences to this one, including studying undifferentiated hearing loss as opposed to specifically the age-related type, and it is not known whether hearing loss of different etiologies also differs in its neurochemical correlates. For all significant results, there were qualitatively similar findings in the LAC as in the RAC, but the findings were much stronger and only significant in the RAC. The $20 \%$ loss of signal observed in the LAC can be potentially explained by spatial effects influencing GABA MRS measurements (Edden and Barker, 2007). Thus, it is possible that in reality the observed neurochemical correlates of tinnitus are bilateral. However, we stress the importance of obtaining direct evidence rather than assuming this to be the case. Although there was a slight excess of left-earpredominant tinnitus subjects ( 8 vs 6 ), there were no significant differences between left and right ear tinnitus even after markedly relaxing statistical thresholds, making tinnitus laterality a very unlikely explanation.

\section{GABA in tinnitus}

We have demonstrated, for the first time, an auditory cortex GABA deficit in human tinnitus subjects. Given the tight matching of the control group for age and hearing loss, this deficit can be specifically attributed to tinnitus itself. Presently, the implications of this finding for understanding tinnitus pathophysiology as a whole are uncertain, although in light of findings in animal tinnitus models (Middleton et al., 2011; Llano et al., 2012), it is likely that this GABA deficiency is responsible for excessive magnitude and lateral spread of cortical responses to thalamic stimulation. Therefore, GABA deficiency may underlie excessive sound-evoked (Gu et al., 2010) and spontaneous (Adjamian et al., 2012) activity that has been observed previously in tinnitus in humans, even after matching for hearing loss and hyperacusis. However, GABA systems may have a more complex role in tinnitus; a recent study found evidence of increased GABAmediated tonic inhibition in the auditory thalami of rats with noise-induced tinnitus (Sametsky et al., 2015). This excess inhibition was in turn linked to abnormal burst firing of thalamic neurons, which has been argued to trigger abnormal cortical activity linked to tinnitus (Llinás et al., 1999). Thus, the net effect of GABA on tinnitus-linked cortical activity may vary according to such factors as anatomical location and receptor type. With regard to the present results, it is possible that GABA deficiency is a primary cause of tinnitus that, in conjunction with hearing loss, removes the necessary inhibition to prevent spontaneous activity in the auditory system from being perceived as tinnitus. In addition to a role in enhancing cortical responses to sounds or spontaneous subcortical activity, GABA deficiency in the auditory cortex might also act in other ways. Various brain structures outside the auditory system, including limbic, parietal, and prefrontal regions, have been implicated in tinnitus (Lockwood et al., 1998; Moazami-Goudarzi et al., 2010; Vanneste et al., 2010; De Ridder et al., 2013); together, these may mediate the entry of the tinnitus percept into conscious perception and mediate its cognitive and affective consequences. The nonprimary auditory cortex shows rich connectivity with many of these regions in 
association with tinnitus (De Ridder et al., 2013; Sedley et al., 2015), and, although there is not yet direct evidence on the subject, it seems possible that GABA changes in the nonprimary auditory cortex might affect entry of the tinnitus signal into wider cortical networks. Because the present data cannot separate GABA changes in the primary from the nonprimary auditory cortex, this possibility should be considered. It is also plausible that GABA deficiency is the direct consequence of chronic stimulation (by tinnitus or its precursors originating subcortically) of the auditory cortex, but we are not aware of any evidence about the effect of chronic sensory stimulation on cortical GABA concentration that could address this possibility. It is also uncertain whether the GABA deficit is a cause or consequence of tinnitus. Although there was not a relationship between tinnitus duration and GABA concentration, which would have favored the GABA deficit being a consequence of tinnitus, this question remains open. Regardless of the exact origin and role of cortical GABA in tinnitus, it seems probable that it is a significant positive force in its pathogenesis, because reduced GABA concentration most likely indicates reduced GABAergic inhibition and therefore a relative excess of excitation in the auditory system. There remains the need for additional understanding of other aspects of GABA systems in tinnitus, such as receptor density, which presently only has limited evidence in humans (Shulman et al., 2000). As well as replicating the present findings, future studies of GABA systems in humans might involve combining GABA measurements using MRS with GABA receptor density measurements using positron emission tomography. In animals, a number of additional measures, such as glutamic acid decarboxylase expression and $\mathrm{GABA}_{\mathrm{A}}$ receptor subunit composition, might also be measured simultaneously. Studies might also examine both acute and chronic tinnitus to establish the temporal order of tinnitus phenomenology and GABA changes and also the effect of chronic physiological auditory stimulation on GABA systems.

\section{Choline in tinnitus}

Our results indicate that auditory cortex choline concentration correlates positively with both tinnitus severity (in terms of distress and possibly loudness) and hearing loss (particularly in the tinnitus group). Choline is strongly influenced by neuronal density (Miller et al., 1996), and GM loss (hence increased WM/GM ratio) increased with hearing loss, as reported previously (Husain et al., 2011). However, given the persistence of observed findings after statistically adjusting for the influence of GM and WH tissue fractions, it seems probable that choline relates directly to hearing loss and tinnitus. Because choline measured by MRS reflects increased neuronal membrane turnover (Rae, 2014), which may relate to plasticity (Gutiérrez-Fernández et al., 2012), and (although acetylcholine barely contributes to the choline signal) correlates strongly with local concentration of acetylcholine (Wang et al., 2008), we cannot presently determine which of these factors is perturbed as a function of hearing loss and tinnitus severity. Additional work to directly measure neuronal plasticity and acetylcholine is required to understand the relationship between choline and tinnitus.

In summary, we have specifically related the presence and severity of tinnitus, after eliminating confounding factors, to non-invasively measured metabolite concentrations in the auditory cortex. The finding of a GABA deficit in tinnitus patients is beyond a homeostatic response to hearing loss, underscores the importance of GABA systems in the pathophysiology of tinnitus, and may help to direct future treatments.

\section{References}

Adjamian P, Sereda M, Zobay O, Hall DA, Palmer AR (2012) Neuromagnetic indicators of tinnitus and tinnitus masking in patients with and without hearing loss. J Assoc Res Otolaryngol 13:715-731. CrossRef Medline

Bauer CA, Brozoski TJ, Holder TM, Caspary DM (2000) Effects of chronic salicylate on GABAergic activity in rat inferior colliculus. Hear Res 147: 175-182. CrossRef Medline

Brozoski TJ, Spires TJ, Bauer CA (2007) Vigabatrin, a GABA transaminase inhibitor, reversibly eliminates tinnitus in an animal model. J Assoc Res Otolaryngol 8:105-118. CrossRef Medline

Brozoski T, Odintsov B, Bauer C (2012) Gamma-aminobutyric acid and glutamic acid levels in the auditory pathway of rats with chronic tinnitus: a direct determination using high resolution point-resolved proton magnetic resonance spectroscopy (H-MRS). Front Syst Neurosci 6:9. CrossRef Medline

Busto U, Sellers EM, Naranjo CA, Cappell H, Sanchez-Craig M, Sykora K (1986) Withdrawal reaction after long-term therapeutic use of benzodiazepines. N Engl J Med 315:854-859. CrossRef Medline

Busto U, Fornazzari L, Naranjo CA (1988) Protracted tinnitus after discontinuation of long-term therapeutic use of benzodiazepines. J Clin Psychopharmacol 8:359-362. Medline

Cacace AT, Silver SM (2007) Applications of magnetic resonance spectroscopy to tinnitus research: initial data, current issues, and future perspectives. Prog Brain Res 166:71-81. CrossRef Medline

De Ridder D, Vanneste S, Weisz N, Londero A, Schlee W, Elgoyhen AB, Langguth B (2014) An integrative model of auditory phantom perception: Tinnitus as a unified percept of interacting separable subnetworks. Neurosci Biobehav Rev 44:16-32. CrossRef Medline

De Ridder D, Vanneste S, Langguth B, Llinas R (2015) Thalamocortical dysrhythmia: a theoretical update in tinnitus. Front Neurol 6:124. CrossRef Medline

Edden RA, Barker PB (2007) Spatial effects in the detection of gammaaminobutyric acid: improved sensitivity at high fields using inner volume saturation. Magn Reson Med 58:1276-1282. CrossRef Medline

Edden RA, Puts NA, Barker PB (2012) Macromolecule-suppressed GABAedited magnetic resonance spectroscopy at 3T. Magn Reson Med 68:657661. CrossRef Medline

Edden RA, Puts NA, Harris AD, Barker PB, Evans CJ (2014) Gannet: A batch-processing tool for the quantitative analysis of gammaaminobutyric acid-edited MR spectroscopy spectra. J Magn Reson Imaging 40:1445-1452. CrossRef Medline

Eggermont JJ (2013) Hearing loss, hyperacusis, or tinnitus: what is modeled in animal research? Hear Res 295:140-149. CrossRef Medline

Ethofer T, Mader I, Seeger U, Helms G, Erb M, Grodd W, Ludolph A, Klose U (2003) Comparison of longitudinal metabolite relaxation times in different regions of the human brain at 1.5 and 3 Tesla. Magn Reson Med 50:1296-1301. CrossRef Medline

Gao F, Wang G, Ma W, Ren F, Li M, Dong Y, Liu C, Liu B, Bai X, Zhao B, Edden RA (2015) Decreased auditory GABA+ concentrations in presbycusis demonstrated by edited magnetic resonance spectroscopy. Neuroimage 106:311-316. CrossRef Medline

Gu JW, Halpin CF, Nam EC, Levine RA, Melcher JR (2010) Tinnitus, diminished sound-level tolerance, and elevated auditory activity in humans with clinically normal hearing sensitivity. J Neurophysiol 104:3361-3370. CrossRef Medline

Gutiérrez-Fernández M, Rodríguez-Frutos B, Fuentes B, Vallejo-Cremades MT, Alvarez-Grech J, Expósito-Alcaide M, Díez-Tejedor E (2012) CDPcholine treatment induces brain plasticity markers expression in experimental animal stroke. Neurochem Int 60:310-317. CrossRef Medline

Han SS, Nam EC, Won JY, Lee KU, Chun W, Choi HK, Levine RA (2012) Clonazepam quiets tinnitus: a randomised crossover study with Ginkgo biloba. J Neurol Neurosurg Psychiatry 83:821-827. CrossRef Medline

Harris AD, Puts NA, Edden RA (2015) Tissue correction for GABA-edited MRS: considerations of voxel composition, tissue segmentation and tissue relaxations. J Magn Reson Imaging. Advance online publication. Retrieved October 8, 2015. doi:10.1002/jmri.24903. CrossRef Medline

Harris AD, Glaubitz B, Near J, John Evans C, Puts NA, Schmidt-Wilcke T, Tegenthoff M, Barker PB, Edden RA (2014) Impact of frequency drift on gamma-aminobutyric acid-edited MR spectroscopy. Magn Reson Med 72:941-948. CrossRef Medline

Husain FT, Medina RE, Davis CW, Szymko-Bennett Y, Simonyan K, Pajor 
NM, Horwitz B (2011) Neuroanatomical changes due to hearing loss and chronic tinnitus: a combined VBM and DTI study. Brain Res 1369: 74-88. CrossRef Medline

Khalfa S, Dubal S, Veuillet E, Perez-Diaz F, Jouvent R, Collet L (2002) Psychometric normalization of a hyperacusis questionnaire. ORL J Otorhinolaryngol Relat Spec 64:436-442. CrossRef Medline

Kilicarslan R, Alkan A, Aralasmak A, Aksoy F, Toprak H, Yetis H, Ozturan O (2014) Magnetic resonance spectroscopy features of Heschl's gyri in patients with unilateral acoustic neuroma: preliminary study. Acad Radiol 21:1501-1505. CrossRef Medline

Lanting CP, De Kleine E, Bartels H, Van Dijk P (2008) Functional imaging of unilateral tinnitus using fMRI. Acta Otolaryngol 128:415-421. CrossRef Medline

Llano DA, Turner J, Caspary DM (2012) Diminished cortical inhibition in an aging mouse model of chronic tinnitus. J Neurosci 32:16141-16148. CrossRef Medline

Llinás RR, Ribary U, Jeanmonod D, Kronberg E, Mitra PP (1999) Thalamocortical dysrhythmia: a neurological and neuropsychiatric syndrome characterized by magnetoencephalography. Proc Natl Acad Sci U S A 96: 15222-15227. CrossRef Medline

Lockwood AH, Salvi RJ, Coad ML, Towsley ML, Wack DS, Murphy BW (1998) The functional neuroanatomy of tinnitus: evidence for limbic system links and neural plasticity. Neurology 50:114-120. CrossRef Medline

Melcher JR, Levine RA, Bergevin C, Norris B (2009) The auditory midbrain of people with tinnitus: abnormal sound-evoked activity revisited. Hear Res 257:63-74. CrossRef Medline

Mescher M, Merkle H, Kirsch J, Garwood M, Gruetter R (1998) Simultaneous in vivo spectral editing and water suppression. NMR Biomed 11: 266-272. CrossRef Medline

Middleton JW, Kiritani T, Pedersen C, Turner JG, Shepherd GM, Tzounopoulos T (2011) Mice with behavioral evidence of tinnitus exhibit dorsal cochlear nucleus hyperactivity because of decreased GABAergic inhibition. Proc Natl Acad Sci U S A 108:7601-7606. CrossRef Medline

Miller BL, Chang L, Booth R, Ernst T, Cornford M, Nikas D, McBride D, Jenden DJ (1996) In vivo 1H MRS choline: correlation with in vitro chemistry/histology. Life Sci 58:1929-1935. CrossRef Medline

Mlynárik V, Gruber S, Moser E (2001) Proton T (1) and T (2) relaxation times of human brain metabolites at 3 Tesla. NMR Biomed 14:325-331. CrossRef Medline

Moazami-Goudarzi M, Michels L, Weisz N, Jeanmonod D (2010) Temporo-insular enhancement of EEG low and high frequencies in patients with chronic tinnitus. QEEG study of chronic tinnitus patients. BMC Neurosci 11:40. CrossRef Medline

Mullins PG, McGonigle DJ, O'Gorman RL, Puts NA, Vidyasagar R, Evans CJ, Edden RA (2014) Current practice in the use of MEGA-PRESS spectroscopy for the detection of GABA. Neuroimage 86:43-52. CrossRef Medline

Naressi A, Couturier C, Castang I, de Beer R, Graveron-Demilly D (2001) Java-based graphical user interface for MRUI, a software package for quantitation of in vivo/medical magnetic resonance spectroscopy signals. Comput Biol Med 31:269-286. CrossRef Medline

Near J, Edden R, Evans CJ, Paquin R, Harris A, Jezzard P (2014) Frequency and phase drift correction of magnetic resonance spectroscopy data by spectral registration in the time domain. Magn Reson Med. Advance online publication. Retrieved October 8, 2015. doi:10.1002/mrm.25094. CrossRef Medline

Newman CW, Jacobson GP, Spitzer JB (1996) Development of the tinnitus handicap inventory. Arch Otolaryngol Head Neck Surg 122:143-148. CrossRef Medline

Noreña AJ, Eggermont JJ (2003) Changes in spontaneous neural activity immediately after an acoustic trauma: implications for neural correlates of tinnitus. Hear Res 183:137-153. CrossRef Medline

Noreña AJ, Farley BJ (2013) Tinnitus-related neural activity: theories of generation, propagation, and centralization. Hear Res 295:161-171. CrossRef Medline

Puts NA, Edden RA (2012) In vivo magnetic resonance spectroscopy of GABA: a methodological review. Prog Nucl Magn Reson Spectrosc 60: 29-41. CrossRef Medline

Rae CD (2014) A guide to the metabolic pathways and function of metabolites observed in human brain $1 \mathrm{H}$ magnetic resonance spectra. Neurochem Res 39:1-36. CrossRef Medline

Sametsky EA, Turner JG, Larsen D, Ling L, Caspary DM (2015) Enhanced $\mathrm{GABA}_{\mathrm{A}}$-mediated tonic inhibition in auditory thalamus of rats with behavioral evidence of tinnitus. J Neurosci 35:9369-9380. CrossRef Medline

Sedley W, Cunningham MO (2013) Do cortical gamma oscillations promote or suppress perception? An under-asked question with an overassumed answer. Front Hum Neurosci 7:595. CrossRef Medline

Sedley W, Gander PE, Kumar S, Oya H, Kovach CK, Nourski KV, Kawasaki H, Howard MA 3rd, Griffiths TD (2015) Intracranial mapping of a cortical tinnitus system using residual inhibition. Curr Biol 25:1208-1214. CrossRef Medline

Seki S, Eggermont JJ (2003) Changes in spontaneous firing rate and neural synchrony in cat primary auditory cortex after localized tone-induced hearing loss. Hear Res 180:28-38. CrossRef Medline

Shulman A, Strashun AM, Seibyl JP, Daftary A, Goldstein B (2000) Benzodiazepine receptor deficiency and tinnitus. Int Tinnitus J 6:98-111. Medline

Tass PA, Adamchic I, Freund HJ, von Stackelberg T, Hauptmann C (2012) Counteracting tinnitus by acoustic coordinated reset neuromodulation. Restor Neurol Neurosci 30:137-159. CrossRef Medline

Tkác I, Starcuk Z, Choi IY, Gruetter R (1999) In vivo 1H NMR spectroscopy of rat brain at $1 \mathrm{~ms}$ echo time. Magn Reson Med 41:649-656. CrossRef Medline

Vanneste S, Plazier M, der Loo Ev, de Heyning PV, Congedo M, De Ridder D (2010) The neural correlates of tinnitus-related distress. Neuroimage 52: 470-480. CrossRef Medline

Wang XC, Du XX, Tian Q, Wang JZ (2008) Correlation between choline signal intensity and acetylcholine level in different brain regions of rat. Neurochem Res 33:814-819. CrossRef Medline

Weisz N, Müller S, Schlee W, Dohrmann K, Hartmann T, Elbert T (2007) The neural code of auditory phantom perception. J Neurosci 27: 1479-1484. CrossRef Medline

Zheng Y, Vagal S, McNamara E, Darlington CL, Smith PF (2012) A doseresponse analysis of the effects of L-baclofen on chronic tinnitus caused by acoustic trauma in rats. Neuropharmacology 62:940-946. CrossRef Medline 